\title{
Prey size affects the costs and benefits of group predation in nymphs of the predatory stink bug Andrallus spinidens (Heteroptera: Pentatomidae)
}

\author{
Daisuke Hyodo $\cdot$ Chihiro Himuro $\cdot$ Kenji Fujisaki
}

Received: 15 January 2014 / Accepted: 17 June 2014/Published online: 6 July 2014

(C) Japan Ethological Society and Springer Japan 2014

\begin{abstract}
Group predation promotes foraging efficiency because it increases the size of prey that can be killed and improves hunting success compared to solitary predation. However, group predation may increase competition among group members during feeding. Earlier studies have focused on the advantages of group predation, but little is known about the costs and benefits of group predation for individual members of the group. Here, we show that the costs and benefits of group predation for individuals of the predatory stink bug Andrallus spinidens vary with prey size in laboratory experiments. We found that when A. spinidens fed on small prey, group predation did not significantly increase foraging efficiency but did increase competition for food among group members. In contrast, when prey was large, group predation promoted foraging efficiency, and competition over food was not detected. Our results suggest that group predation by A. spinidens nymphs is advantageous for individual members because it enables each member to hunt larger prey that could not be hunted alone. However, when group size was large or prey size was small, group predation increased competition among group members.
\end{abstract}

\section{Hyodo ( $\square)$}

Laboratory of Insect Ecology, Graduate School of Agriculture,

Kyoto University, Kitashirakawaoiwake-cho, Sakyo-ku,

Kyoto 606-8502, Japan

e-mail: hyodo83@kais.kyoto-u.ac.jp

\section{Himuro}

Laboratory of Evolutionary Ecology, Graduate School of Environment and Life Science, Okayama University, 1-1-1,

Tsushima-naka, Kita-ku, Okayama 700-8530, Japan

K. Fujisaki

Akaiwa, Okayama Prefecture, Japan
Keywords Group predation · Group size · Prey size · Asopinae $\cdot$ Andrallus spinidens

\section{Introduction}

Group predation occurs in a wide range of taxa, including insects (e.g., Chadab and Rettenmeyer 1975; Dejean et al. 2013), social spiders (e.g., Burgess 1976: Kim et al. 2005), fish (e.g., Bshary 2006), birds (e.g., Bednarz 1988), and mammals (e.g., Creel and Creel 1995). In particular, social carnivores have been the focus of much research on group hunting behavior (reviewed by Bailey et al. 2013; Krause and Ruxton 2002). Group predation is infrequent in insects, but has been reported in eusocial insects (Breed et al. 1987; Schatz et al. 1997; Daly-Schveitzer et al. 2007), first instar larvae of aphidophagous ladybird beetles (Hemptinne et al. 2000; Moore et al. 2012), some assassin bug nymphs (Inoue 1985; Dejean et al. 2013), and nymphs and adults of some predaceous pentatomids (Manley 1982; Matlock 2005). Group predation promotes foraging efficiency because it allows the capture of larger prey and can improve hunting success compared to solitary predation (Inoue 1985; Bednarz 1988; Creel and Creel 1995). However, if group size is large or prey size is small, group predation may increase competition among group members during feeding (Krause and Ruxton 2002). Thus, the costs and benefits of group predation should depend on the combination of group size and prey size.

While many studies have examined the costs and benefits of group predation, less attention has been paid to the costs and benefits for individuals in the group. To clarify individual costs and benefits, examining predation behavior with different group sizes and prey sizes is important. This is difficult with vertebrate predators because of their long 
life span, complex social ecology, and low population density. Therefore, we investigated the costs and benefits of group predation at the individual level with nymphs of a predatory stink bug.

The predatory stink bug Andrallus spinidens is widely distributed in tropical and warm-temperate zones worldwide. This bug inhabits grasslands, paddy fields, and vegetable fields and kills many types of lepidopteran, coleopteran, and hymenopteran larvae (Tomokuni et al. 1993). In fields, several A. spinidens nymphs are commonly found feeding on a single prey (Manley 1982; Fig. 1). The gregarious behavior is most strongly expressed in the first two instars and to a lesser degree in the third instar. Fourth and fifth instars are mostly solitary (Manley 1982). A. spinidens uses extraoral digestion and attacks by inserting stylets into the prey body (Cohen 1998; Zibaee et al. 2012). This attack behavior is easy to observe, making the nymphs of $A$. spinidens well suited for tests on the individual effects of group predation.

In this study, we examined the costs and benefits of group predation at the individual level in A. spinidens nymphs. Capture success of juvenile predators generally declines as prey size/predator size ratio increases (Nakazawa et al. 2013), and handling time increases as prey size increases (Dixon 1959). To study the effect of group predation on the prey size, we marked nymphs for individual identification and conducted behavioral observations. We counted the number of attacks by each nymph, recorded hunting time, and estimated predation success and weight gain. We compared these data between different group sizes and prey sizes.

\section{Materials and methods}

\section{Study species}

Adults and nymphs of the predatory stink bug A. spinidens were collected from sweet potato fields in Takanabe, Miyazaki Prefecture, Japan on 10-11 September 2007 and 2-5 September 2008. A. spinidens nymphs were usually found in groups of 2-80 individuals (Hyodo, unpublished data). Each group was reared in jars (top: $120 \mathrm{~mm}$ diameter; bottom: $100 \mathrm{~mm}$ diameter; $55 \mathrm{~mm}$ height) containing wet cotton to maintain humidity. The entrances of jars were covered with nylon mesh. The jars were kept under 16-h light and 8-h dark photoperiod conditions (light period, 0700-2300 hours) at $25 \pm 2{ }^{\circ} \mathrm{C}$. Fourth to sixth instar larvae of Spodoptera litura were used as prey. We provided distilled water and one prey per nymph every $2-3$ days. We collected newly molted adults and placed two to three males and two to three females in jars that were kept under the same conditions as the nymphs. The deposited eggs
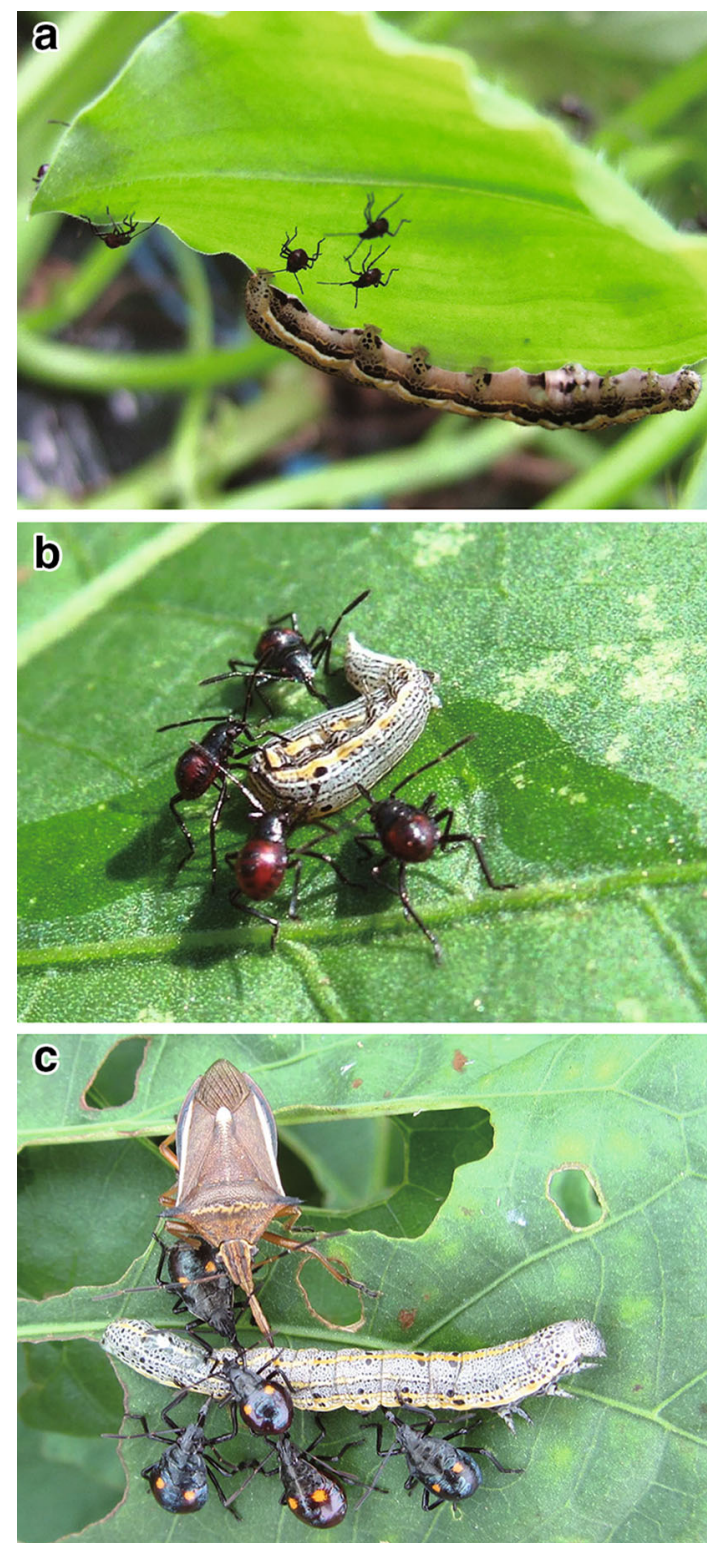

Fig. 1 Group predation by the stink bug Andrallus spinidens. a A group of second instar nymphs of $A$. spinidens pursuing a caterpillar of Aedia leucomelas. $\mathbf{b}$ Group feeding by second instar nymphs of $A$. spinidens. $\mathbf{c}$ A group of third and fourth instar nymphs of $A$. spinidens feeding on a caterpillar with an adult

were transferred to Petri dishes (90 mm diameter, $20 \mathrm{~mm}$ height) with cotton moistened with distilled water. First instar nymphs only suck water until they molt into the second instar (Manley 1982). In all experiments, we used $\mathrm{F}_{1}$ and $\mathrm{F}_{2}$ instar nymphs within $24 \mathrm{~h}$ of molting.

We used $S$. litura as prey in all experiments because they were observed being preyed upon by A. spinidens in the field (Shintani et al. 2010). S. litura was reared on an artificial diet (Insecta-LFS; Nihon Nosan Kogyo, Yokohama, Japan) at $25 \pm 2{ }^{\circ} \mathrm{C}$ under a 16-h/8-h (light/dark) cycle. In the experiments, we used third, fourth, and sixth 
instar larvae of $S$. litura as prey, which had mean weights of $15.1 \pm 0.7 \mathrm{mg}(\mathrm{SE}, n=41), 34.4 \pm 1.6 \mathrm{mg}(n=33)$, and $674.7 \pm 20.1 \mathrm{mg}(n=21)$, respectively.

\section{Experiment}

To examine the costs and benefits of group predation for individual A. spinidens nymphs, we recorded the number of attacks, hunting time, estimated predation success, and weight gain for each individual. Then, we compared these values among different group sizes. A. spinidens nymphs were individually marked with a paint marker (paint marker PC-1 M; Mitsubishi, Tokyo, Japan) and weighed using an electronic balance (JPN-189 W; Chyo Balance, Kyoto, Japan). One, two, or four nymphs were placed in Petri dishes (90 $\mathrm{mm}$ diameter, $20 \mathrm{~mm}$ height) having cotton moistened with distilled water. In tests of two and four individuals, the nymphs used were from the same egg mass. We then added one larva of third, fourth, or sixth instar S. litura to the center of the Petri dish. We prepared 16 replications for single nymph faced with third and fourth instar $S$. litura and two nymphs faced with fourth instar S. litura; 20 replications for two nymphs faced with third instar S. litura; 15 replications for four nymphs faced with third and fourth instar S. litura; 19 replications for single and two nymphs faced with sixth instar S. litura; and 17 replications for four nymphs faced with sixth instar $S$. litura. We recorded individual's attack behaviors for $2 \mathrm{~h}$ with uninterrupted direct observation or a digital video camera (NV-GS320; Panasonic, Tokyo, Japan). We recorded the following predator behaviors: (1) touch: light contact on the prey with its antennae or other parts of its body; (2) attack: insertion of stylets into the prey body; (3) prey paralysis: immobilization of the prey after insertion of its stylets; and (4) retreats: the predator retreats after defensive movements of the prey (Lemos et al. 2005). We recorded the number of successful attacks as the number that led to prey paralysis. We defined hunting time as the time from "touch" to "prey paralysis". If the predators failed to eat within $2 \mathrm{~h}$, the test was terminated. After the predators stopped feeding, they were weighed, and weight gain was calculated as the final weight minus initial weight. All experiments were started between 1300 and 1900 hours.

\section{Statistical analysis}

We used a two-way ANOVA to analyze the number of attacks and hunting time using prey instar and predator group size as factors for categorical data. We used Tukey's honest significant difference (HSD) post hoc test when the ANOVA showed a significant $P$ value $(P<0.05)$. We used Fisher's exact probability test to analyze the predation success of $A$. spinidens nymphs on S. litura larvae. We compared the weight gain of $A$. spinidens nymphs using a Kruskal-Wallis test with sequential Bonferroni correction. All analyses were performed using JMP v.5.1.2 (SAS Institute).

\section{Results}

Number of attacks per nymph

Both the group size of $A$. spinidens and the prey instar significantly influenced the number of attacks by each nymph $(P<0.001$, two-way ANOVA; Table 1$)$. A. spinidens nymphs made significantly more attacks when hunting upon sixth instar larvae of S. litura than hunting upon third and fourth instar larvae ( $P<0.05$, Tukey's HSD). In the test of sixth instar larvae, groups of four predators made significantly more attacks per individual nymphs than groups of two or single predators $(P<0.05$, Tukey's HSD).

\section{Hunting time}

Both the group size of $A$. spinidens and the size of prey instars significantly influenced the duration of hunting time from "touch" to "prey paralysis" $(P<0.01$, two-way ANOVA; Fig. 2). When hunting sixth instar larvae of $S$. litura, hunting time was significantly longer than when hunting upon third and fourth instar larvae $(P<0.05$, Tukey's HSD). Hunting time was significantly longer for single A. spinidens compared to groups of four when preying upon sixth instar larvae $(P<0.05$, Tukey's HSD).

\section{Predation success}

Predation success was significantly higher for groups of four and groups of two when preying upon third and fourth instar larvae, and for single individuals preying upon third instar larvae than for single individuals preying upon sixth instar larvae $(P<0.05$, Fisher's exact probability test; Fig. 3).

Table 1 Influence of prey instar and group size on the number of attacks by each Andrallus spinidens nymph

\begin{tabular}{lrrrr}
\hline Factor & \multicolumn{1}{c}{ SS } & $d f$ & $F$ value & $P$ value \\
\hline Prey instar & 1508.6 & 2 & 113.99 & $<0.001$ \\
Group size & 116.9 & 2 & 8.83 & $<0.001$ \\
Prey instar $\times$ Group size & 152.4 & 4 & 5.76 & $<0.001$ \\
\hline
\end{tabular}




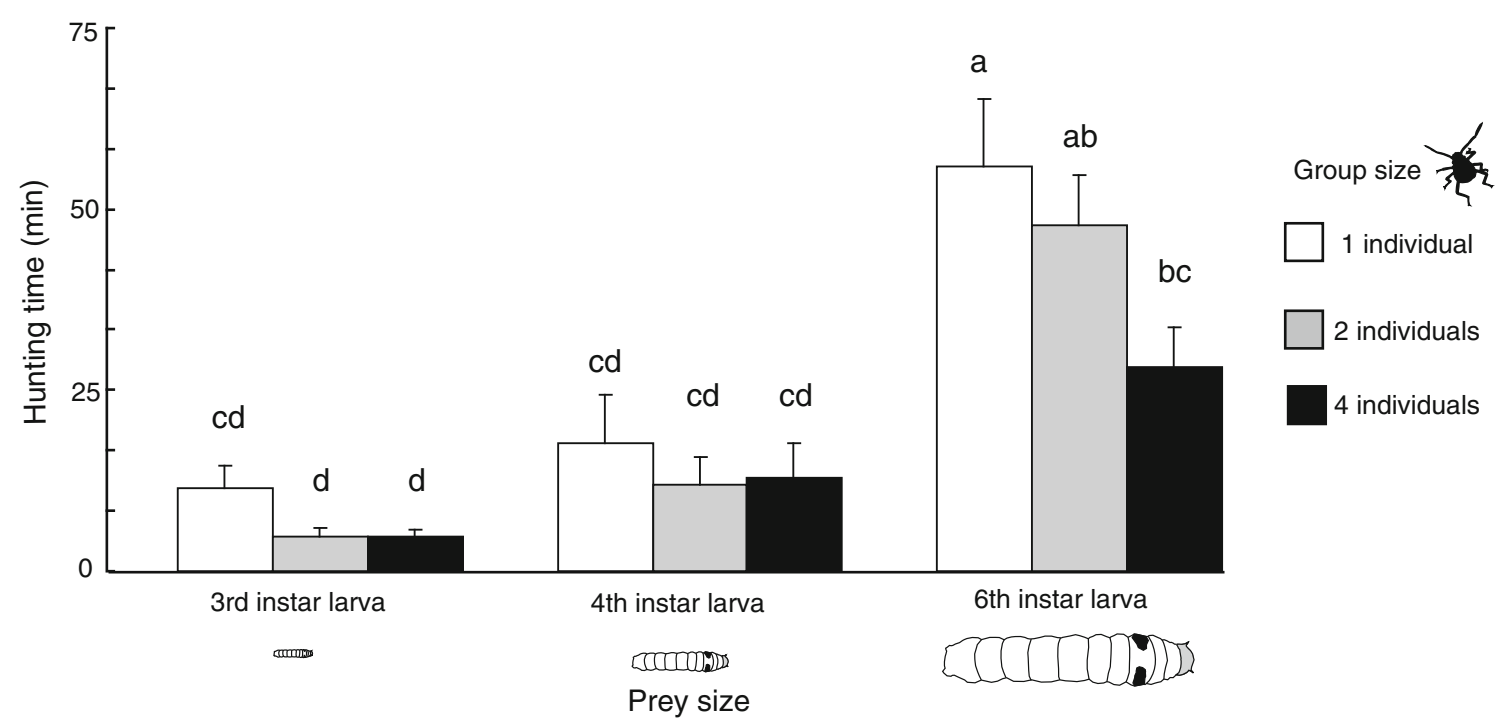

Fig. 2 Hunting time of Andrallus spinidens nymphs preying on Spodoptera litura larvae. Different letters indicate statistically significant differences according to Tukey's HSD test $(P<0.05)$

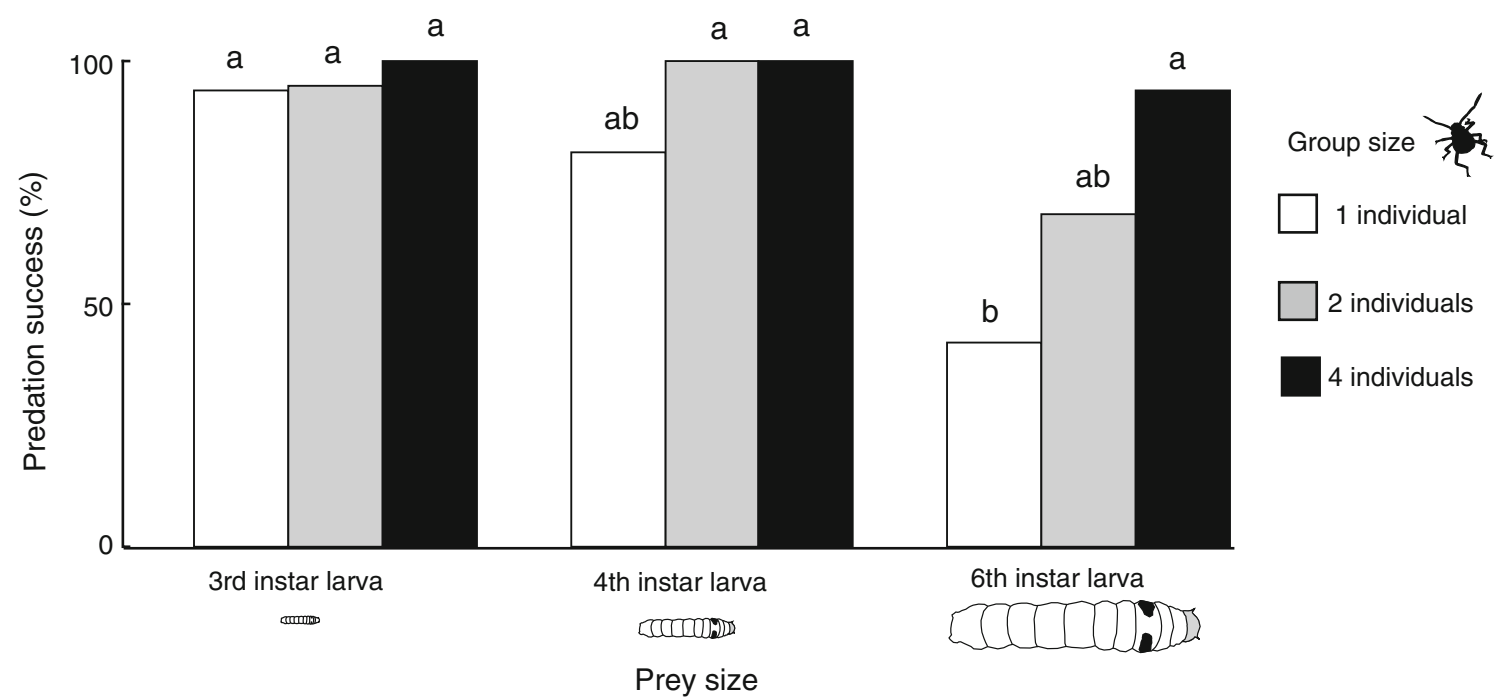

Fig. 3 Predation success rate of Andrallus spinidens nymphs on Spodoptera litura larvae. Different letters indicate statistically significant differences according to Fisher's exact probability test with sequential Bonferroni correction $(P<0.05)$

Weight gain

Mean weight gain differed significantly among group sizes (Fig. 4). In tests with third instar S. litura larvae, weight gain differed among all three group sizes with smaller groups having greater individual weight gain (Kruskal-Wallis test, $P<0.05$ ). In tests with fourth instar larvae, single individuals showed greater weight gain than individuals in groups of four (Kruskal-Wallis test, $P<0.05)$. When hunting sixth instar larvae, individual predator's weight gain was greater when hunting in groups of four than in groups of two, and weight gain for solitary individuals was intermediate (Kruskal-Wallis test, $P<0.05)$.

\section{Discussion}

We found that the costs and benefits of group predation by A. spinidens nymphs varied with prey size. In tests with small prey, no significant differences were detected in the number of attacks by each nymph, hunting time, or predation success due to the group size of $A$. spinidens. Under these conditions, mean weight gain was significantly higher 


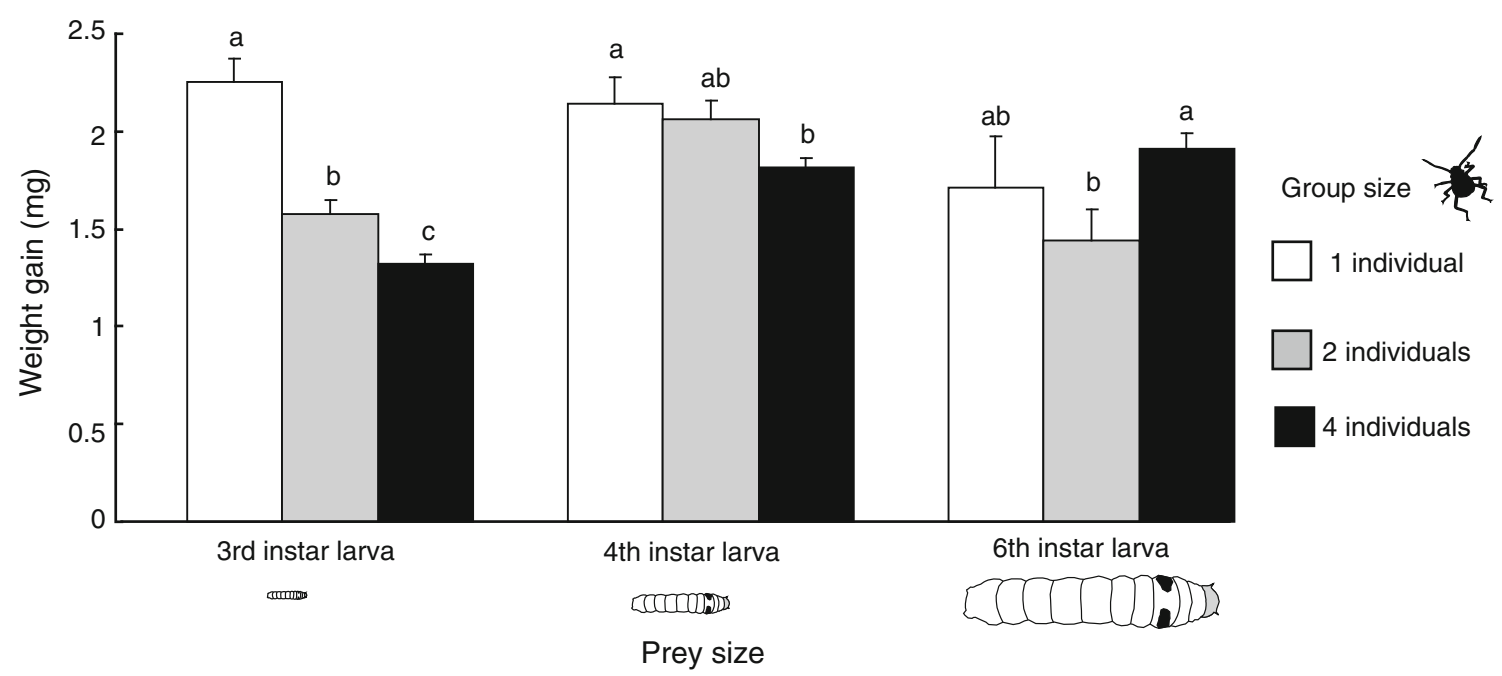

Fig. 4 Weight gain of Andrallus spinidens nymphs preying on Spodoptera litura larvae. Different letters indicate statistically significant differences according to a Kruskal-Wallis test with sequential Bonferroni correction $(P<0.05)$

for single individuals than for grouped individuals. Thus, group predation did not significantly promote foraging efficiency with small prey and increased exploitation competition among group members over food. In contrast, in experiments with sixth instar prey larvae, groups of four individuals captured prey with fewer attacks and shorter hunting times, and achieved higher predation success than single individuals. No significant difference was noted in weight gain between single and grouped individuals. Thus, with large prey, group predation for groups of at least four individuals promoted foraging efficiency, and enough food for four individuals.

Such a difference in costs and benefits with the prey size and group size is consistent with results from other group hunting predators, including carnivorous animals, spiders, and insects (Caraco and Wolf 1975; Inoue 1985; Kim et al. 2005). For example, in the African wild dog Lycaon pictus, predation success, prey mass, and the probability of multiple kills increased with the number of adults (Creel and Creel 1995). Predation success and the range of prey species attacked have been shown to increase with group size in lions (Funston et al. 2001) and hyenas (Holekamp et al. 1997). However, data from a range of social predators suggest that hunting success initially increases, then levels off or even declines with group size despite cooperation among hunters (Caraco and Wolf 1975; MacNulty et al. 2012).

This study clearly showed that the costs and benefits of group predation for individual nymphs of $A$. spinidens varied with prey size, and suggested that group predation by $A$. spinidens nymphs is advantageous when hunting large prey. Nakazawa et al. (2013) indicated that capture success of juvenile predators generally declines as the prey size/predator size ratio increases. These results suggest that group predation is favored by early nymphs because of their smaller size and narrower range of prey than older, larger nymphs. This is supported by field observations that group predation by A. spinidens nymphs occurs most frequently in second, and to a lesser degree, third instars, while fourth and fifth instars are mostly solitary hunters (Manley 1982). Some other predaceous pentatomids are also reported to be gregarious in the early nymphal periods (see De Clercq 2000), indicating that foraging efficiency may promote group living in the younger nymphs of these insects as well. Further studies examining the costs and benefits of group predation for older nymphs will contribute to understanding mechanism of gregarious behavior of predaceous pentatomids.

Acknowledgments We thank Dr Y. Shintani, Minami Kyushu University, for kindly supplying the insects. We also thank Prof. T. Nishida, University of Shiga Prefecture, for providing valuable information, and to all of the members of the Laboratory of Insect Ecology, Graduate School of Agriculture, Kyoto University, for their support throughout this study. The paper was improved by the comments of Prof. K. Matsuura, Kyoto University.

\section{References}

Bailey I, Myatt JP, Wilson AM (2013) Group hunting within the Carnivora: physiological, cognitive and environmental influences on strategy and cooperation. Behav Ecol Sociobiol 67:1-17

Bednarz JC (1988) Cooperative hunting in Harris' hawks (Parabuteo unicinctus). Science 239:1525-1527

Breed MD, Fewell JH, Moore AJ, Williams KR (1987) Graded recruitment in a ponerine ant. Behav Ecol Sociobiol 20:407-411 
Bshary R, Hohner A, Ait-el-Djoudi K, Fricke H (2006) Interspecific communicative and coordinated hunting between groupers and giant moray eels in the Red sea. PLoS Biol 4:2393-2398

Burgess JW (1976) Social spiders. Sci Am 234:100-106

Caraco T, Wolf LL (1975) Ecological determinants of group sizes of foraging lions. Am Nat 109:343-352

Chadab R, Rettenmeyer CW (1975) Mass recruitment by army ants. Science 188:1124-1125

Cohen AC (1998) Solid-to-liquid feeding: the inside(s) story of extraoral digestion in predaceous Arthropoda. Am Entomol 44:103-117

Creel S, Creel NM (1995) Communal hunting and pack size in African wild dogs, Lycaon pictus. Anim Behav 50:1325-1339

Daly-Schveitzer S, Beugnon G, Lachaud J-P (2007) Prey weight and overwhelming difficulty impact the choice of retrieval strategy in the Neotropical and Gnamptogenys sulcata (F. Smith). Insect Soc 54:319-328

De Clercq P (2000) Predaceous stinkbugs (Pentatomidae: Asopinae). In: Schaefer CW, Panizzi AR (eds) Heteroptera of economic importance. CRC, Boca Raton, pp 737-789

Dejean A, Revel M, Azémar F, Roux O (2013) Altruism during predation in an assassin bug. Naturwissenschaften 100:913-922

Dixon AFG (1959) An experimental study of the searching behaviour of the predatory coccinellid beetle Adalia decempunctata (L.). J Anim Ecol 28:259-281

Funston PJ, Mills MGL, Biggs HC (2001) Factors affecting the hunting success of male and female lions in the Kruger National Park. J Zool Lond 253:419-431

Hemptinne J-L, Gaudin M, Dixon AFG, Lognay G (2000) Social feeding in ladybird beetles: adaptive significance and mechanism. Chemoecology 10:149-152

Holekamp KE, Smale L, Berg R, Cooper SM (1997) Hunting rates and hunting success in the spotted hyena (Crocuta crocuta). J Zool Lond 242:1-15

Inoue H (1985) Group predatory behavior by the assassin bug Agriosphodrus dohrni Signoret (Hemiptera: reduviidae). Res Popul Ecol 27:255-264

Kim KW, Krafft B, Choe JC (2005) Cooperative prey capture by young subsocial spidersI. Functional value. Behav Ecol Sociobiol 59:92-100
Krause J, Ruxton GD (2002) Living in groups. Oxford University Press, Oxford

Lemos WP, Zanuncio JC, Serrão JE (2005) Attack behavior of Podisus rostralis (Heteroptera: Pentatomidae) adults on caterpillars of Bombyx mori (Lepidoptera: Bombycidae). Braz Arch Biol Technol 48:975-981

MacNulty DR, Smith DW, Mech LD, Vucetich JA, Packer C (2012) Nonlinear effects of group size on the success of wolves hunting elk. Behav Ecol 23:75-82

Manley GV (1982) Biology and life history of the rice field predator Andrallus spinidens F. (Hemiptera: Pentatomidae). Entomol News 93:19-24

Matlock RB (2005) Impact of prey size on prey capture success, development rate, and survivorship in Perillus bioculatus (Heteroptera: Pentatomidae), a predator of the Colorado potato beetle. Environ Entomol 34:1048-1056

Moore MP, Burt CR, Whitney TD, Hastings SA, Chang GC (2012) Does social feeding improve larval survival of the two-spotted lady beetle, Adalia bipunctata? J Insect Sci 12:101

Nakazawa T, Ohba S-Y, Ushio M (2013) Predator-prey body size relationships when predators can consume prey larger than themselves. Biol Lett 9 doi:10.1098/rsbl_2012_1193

Schatz B, Lachaud J-P, Beugnon G (1997) Graded recruitment and hunting strategies linked to prey weight and size in the ponerine ant Ectatomma ruidum. Behav Ecol Sociobiol 40:337-349

Shintani Y, Masuzawa Y, Hirose Y, Miyahara R, Watanabe F, Tajima J (2010) Seasonal occurrence and diapause induction of a predatory bug Andrallus spinidens (F.) (Heteroptera: Pentatomidae). Entomol Sci 13:273-279

Tomokuni M, Yasunaga T, Takai M, Yamashita I, Kawamura M, Kawasawa T (1993) A field guide to Japanese bugs: terrestrial heteropterans, vol 1. Zenkoku Noson Kyoiku Kyokai, Tokyo (in japanese)

Zibaee A, Hoda H, Fazeli-Dinan M (2012) Role of proteases in extraoral digestion of a predatory bug Andrallus spinidens. J Insect Sci 12:51 